\title{
Simple Synthesis and Characterization of Hexagonal and Ordered Al-MCM-41 from Natural Perlite
}

\author{
Hongyun Chen ${ }^{1,2}$, Siyao Fu ${ }^{1}$, Liangjie Fu $1,2,3 \oplus$, Huaming Yang $1,2,3, * \mathbb{C}$ and Deliang Chen ${ }^{4, *}$ \\ 1 Centre for Mineral Materials, School of Minerals Processing and Bioengineering, Central South University, \\ Changsha 410083, China; chenhongyun@csu.edu.cn (H.C.); fusiyao@csu.edu.cn (S.F.); \\ franch@csu.edu.cn (L.F.) \\ 2 Hunan Key Lab of Mineral Materials and Application, Central South University, Changsha 410083, China \\ 3 Key Lab of Clay Mineral Functional Materials in China Building Materials Industry, Central South \\ University, Changsha 410083, China \\ 4 School of Chemical Engineering and Energy Technology, School of Materials Science and Engineering, \\ Dongguan University of Technology, Dongguan 523808, China \\ * Correspondence: hmyang@csu.edu.cn (H.Y.); dlchen@dgut.edu.cn (D.C.); Tel.: +86-731-88830549 (H.Y.)
}

Received: 27 March 2019; Accepted: 22 April 2019; Published: 30 April 2019

\begin{abstract}
Silica reagents are expensive and toxic for use in the synthesis of mesoporous silica materials. It is imperative to take an interest in green silicon sources. In this paper, we report the synthesis of hexagonal and ordered aluminum-containing mesoporous silica materials (Al-MCM-41) from natural perlite mineral without addition of silica or aluminum reagents. A pretreatment process involving acid leaching, alkali leaching, and strongly acidic cation exchange resins treatment was critical to obtain silicon and aluminum sources from natural perlite mineral. The Al-MCM-41 material was synthesized via a hydrothermal reaction with hexadecyl trimethyl ammonium bromide $(\mathrm{CTAB})$ as the template and subsequent calcination. The resulting mesophase had a hexagonal and ordered mesoporous structure, confirmed by small-angle X-ray diffraction (SAXRD) and transmission electron microscopy (TEM). Al-MCM-41 material had a high Brunauer-Emmet-Teller (BET) surface area of $1024 \mathrm{~m}^{2} / \mathrm{g}$, pore volume of $0.72 \mathrm{~cm}^{3} / \mathrm{g}$ and an average pore diameter of $2.8 \mathrm{~nm}$ with a pore size distribution centered at $2.5 \mathrm{~nm}$. The thermal behavior of the as-synthesized samples during calcination was investigated by thermogravimetry (TG) and differential thermogravimetry (DTG) analysis. The Al-MCM-41 material showed a negative surface charge in aqueous solution with the $\mathrm{pH}$ value ranging from 2 to 13 . The variations of chemical structures from natural perlite to Al-MCM-41 were traced by wide-angle X-ray diffraction (WAXRD) and Fourier-transform infrared spectroscopy (FTIR). A proposed mechanism for the synthesis of hexagonal and ordered mesoporous silica materials from natural perlite is discussed.
\end{abstract}

Keywords: natural perlite; nanoporous materials; Al-MCM-41; hydrothermal treatment; mechanism

\section{Introduction}

MCM-41, one of the members of M41S reported by scientists at the Mobil Research \& Development Corporation in 1992, is a hexagonal and ordered mesoporous silica material, with uniform mesopores [1,2]. Since the discovery of MCM-41, researchers have taken an interest in its synthesis and application because of its large internal surface, high thermal and hydrothermal stability, possibility of controlling the pore dimension, and potential acidity. Indeed, MCM- 41 has been widely studied in adsorption [3-6], $\mathrm{CO}_{2}$ capture [7-9], catalysis [10-12], drug delivery [13,14], and biomedical applications [15] in the last five years. Traditional mesoporous silica materials were synthesized with sodium silicate, tetraethyl orthosilicate, or tetramethyl orthosilicate as silicon sources. 
These commercial silicon sources were expensive and toxic, potentially introducing pollution during preparation. Researchers, therefore, became interested in cheaper and greener silicon sources instead of silicon-containing chemical reagents. Natural silicate minerals, which have been widely used in various fields [16-19], were suitable for alternative silicon sources due to the advantage of abundant resources, cheapness, and high contents of silicon dioxide. Therefore, silicate minerals had been considered as green silicon sources to synthesize mesoporous silica materials. Ali-dahmane et al. reported the successful synthesis of MCM-41 from bentonite with a Brunauer-Emmet-Teller (BET) surface area of $494 \mathrm{~m}^{2} / \mathrm{g}$ [20]; their work resolved the problem that laboratory reagents were expensive and toxic for the large-scale production of MCM-41 and revealed the relationship between the structural properties of MCM-41 and the mineral phase contents of Algerian bentonite [20]. Yu et al. [21] used diatomite as silicon and aluminum sources to successfully synthesize MCM-41 with ionic liquid 1-hexadecyl-3-methylimidazolium bromide as the template. Jin et al. [22] indicated that highly ordered MCM-41 with a surface area of $1030 \mathrm{~m}^{2} / \mathrm{g}$ was prepared by leaching of sepiolite and sequent hydrothermal synthesis in $\mathrm{NaOH}$ solution with hexadecyltrimethylammonium bromide as the template. In addition, Zhou et al. [23] reported that a mesoporous aluminosilicate molecular sieve $\left(524 \mathrm{~m}^{2} / \mathrm{g}\right) \mathrm{was}$ synthesized with halloysite as the silicon source. Our group had also synthesized MCM-41 materials with a surface area of 500-1040 $\mathrm{m}^{2} / \mathrm{g}$ from natural silicate minerals such as talc [24], attapulgite [25], bentonite [26], diatomite [27], halloysite [28], kaolin [29], and rectorite [30]. These results showed that natural silicate minerals could be used to synthesize mesoporous silica materials. However, to the best of our knowledge, there is no report concerning the use of natural perlite mineral for the preparation of mesoporous silica materials.

Above all, natural silicate minerals are useful for the preparation of mesoporous silica materials as they serve both as a matrix and source of $\mathrm{Si}$ and $\mathrm{Al}$ precursors. The mineral, perlite, is a glassy aluminosilicate material representing a hydrous form of obsidian [31]. The reason for its formation is that the volcanic lava cannot form crystals during the process of hardening due to a short cooling time [31]. However, a silica-rich composition is formed during the fast cooling process. Therefore, perlite consists of high contents of silicon dioxide. It remains possible to synthesize mesoporous silica materials according to previous reports. Our work focuses on the production of silicon and aluminum sources from natural perlite mineral instead of silica or aluminum reagents and the synthesis of aluminum-containing mesoporous silica materials (Al-MCM-41) via hydrothermal treatment and subsequent calcination. This novel strategy for synthesizing Al-MCM-41 could avoid the use of expensive laboratory reagents such as silicon and aluminum sources and be environmentally friendly and cheap. The hexagonal and ordered mesoporous structure of Al-MCM-41 was confirmed by small-angle X-ray diffraction (SAXRD) and transmission electron microscopy (TEM). The variations of chemical structures from natural perlite to Al-MCM-41 were traced using wide-angle X-ray diffraction (WAXRD) and Fourier-transform infrared spectroscopy (FTIR). A possible mechanism for the formation of Al-MCM-41 from natural perlite is discussed.

\section{Materials and Methods}

\subsection{Raw Materials and Reagents}

The chemical composition (wt \%) of natural perlite obtained from Xinyang, Henan, China was $\mathrm{SiO}_{2} 70.76 \%, \mathrm{Al}_{2} \mathrm{O}_{3} 11.58 \%, \mathrm{~K}_{2} \mathrm{O} 3.43 \%, \mathrm{Na}_{2} \mathrm{O} 2.59 \%, \mathrm{CaO} 0.92 \%, \mathrm{Fe}_{2} \mathrm{O}_{3}$ 0.79\%, $\mathrm{MgO} 0.55 \%, \mathrm{TiO}_{2}$ $0.09 \%, \mathrm{MnO}_{2}$ 0.07\%, $\mathrm{Rb}_{2} \mathrm{O} 0.03 \%, \mathrm{ZrO}_{2}$ 0.01\%, $\mathrm{SrO} 0.01 \%$, $\mathrm{PbO} 0.01 \%$, and $9.16 \%$ of volatiles. Strongly acidic cation exchange resins were purchased from Sinopharm Chemical Reagent Co. Ltd. (Shanghai, China). All reagents were analytical grade and used without further purification.

\subsection{Materials Synthesis}

Al-MCM-41 were synthesized with natural perlite mineral as silicon and aluminum sources via hydrothermal reaction and subsequent calcination. Three grams of perlite was reacted with $150 \mathrm{~mL}$ of 
$6 \mathrm{M} \mathrm{HCl}$ solution at $80^{\circ} \mathrm{C}$ for $4 \mathrm{~h}$ in an oil bath. Solid samples (acid-leached samples) were obtained from the cooling suspension through filtering and repeatedly washed with deionized water until no acid was detected in the filtrate. The acid-leached samples were ground into fine powders after drying. Three grams of fine powders was mixed with solid $\mathrm{NaOH}$ in a $1: 1$ ratio. After heating at $100{ }^{\circ} \mathrm{C}$ in air for $2 \mathrm{~h}$ with a ramping rate of $5^{\circ} \mathrm{C} / \mathrm{min}$ in a furnace, the mixture was dispersed in deionized water $(50 \mathrm{~mL})$. The suspension was stirred for $12 \mathrm{~h}$ at room temperature and filtered. The $\mathrm{pH}$ value of the filtrate was adjusted to 13.30 with strongly acidic cation exchange resins. A total of $0.5 \mathrm{~g}$ of CTAB was dissolved in $10 \mathrm{~mL}$ of deionized water, and the filtrate was added to form a mixture under vigorous stirring. The $\mathrm{pH}$ value of the mixture was adjusted to 9.0 by $0.5 \mathrm{M} \mathrm{HCl}$ solutions. After stirring at $60{ }^{\circ} \mathrm{C}$ for $2 \mathrm{~h}$ in a water bath, the mixture was transferred into a $100 \mathrm{~mL}$ Teflon-lined steel autoclave and statically heated at $110^{\circ} \mathrm{C}$ for $24 \mathrm{~h}$. After cooling to room temperature, as-synthesized samples (ASSs) were obtained through filtration, thoroughly washed with anhydrous ethanol and deionized water, and dried at $80^{\circ} \mathrm{C}$ for $4 \mathrm{~h}$. The ASSs were calcined at $550{ }^{\circ} \mathrm{C}$ in air for $6 \mathrm{~h}$ with the ramping rate of $2{ }^{\circ} \mathrm{C} / \mathrm{min}$ in a furnace to produce a white powder of Al-MCM-41.

\subsection{Characterization}

The chemical composition of natural perlite was measured using a Bruker S4 Pioneer X-ray fluorescence spectroscopy (Bruker AXS, Karlsruhe, Germany). X-ray diffraction (XRD) measurements of the samples were performed with a Bruker-AXS D8 Advance diffractometer (Bruker AXS, Karlsruhe, Germany) using $\mathrm{Cu} \mathrm{K} \alpha$ radiation $(\lambda=0.15406 \mathrm{~nm})$ at a scan rate of $2^{\circ} / \mathrm{min}$, over the scanning range $2 \theta=1.5^{\circ}-10^{\circ}$ for small-angle $X R D$ (SAXRD) and $2 \theta=10^{\circ}-80^{\circ}$ for wide-angle XRD (WAXRD). Transmission electron microscopy images of mesoporous silica materials were obtained using a JEOL JEM-2100F system (12052, JEOL, Tokyo, Japan) operating at $200 \mathrm{kV}$. A N $\mathrm{N}_{2}$ adsorption-desorption isotherm and pore size distribution curve of mesoporous silica materials were recorded at $77 \mathrm{~K}$ and analyzed using a Quantachrome NOVA 4200e surface area and pore size analyzer (Quantachrome, Boynton Beach, FL, USA). Thermogravimetry (TG) and differential thermogravimetry (DTG) analysis of ASSs were conducted using a Mettler-Toledo TGA/DSC3+/1600LF thermal analyzer (Mettler-Toledo, Zurich, Switzerland) at a heating rate of $10{ }^{\circ} \mathrm{C} / \mathrm{min}$ under an air atmosphere. Zeta potentials of mesoporous silica materials were measured with a Zetasizer Delsa 440sx instrument (Malvern Instruments Ltd., Malvern, UK) by mixing $0.5 \%$ sample with $0.01 \mathrm{M} \mathrm{KCl}$ solution. The $\mathrm{pH}$ value was adjusted by dripping $0.1 \mathrm{M} \mathrm{HCl}$ or $0.1 \mathrm{M} \mathrm{NaOH}$ solution. Fourier-transform infrared (FTIR) spectra of the samples were obtained between 4000 and $400 \mathrm{~cm}^{-1}$ using a Nicolet Nexus 670 FTIR spectrophotometer (Thermo Company, Waltham, MA, USA) with KBr pellet.

\section{Results and Discussion}

\subsection{Phase and Morphology Analysis}

Figure 1 shows SAXRD patterns of ASSs and Al-MCM-41. SAXRD patterns of Al-MCM-41 clearly showed (100), (110), (200), and (210) diffraction peaks at $2.35^{\circ}, 4.07^{\circ}, 4.70^{\circ}$, and $6.20^{\circ}$, respectively. The relative intensity of the (100) diffraction peak was stronger than that of the other three diffraction peaks. These diffraction peaks proved the existence of the hexagonal and ordered mesoporous structure in synthesized Al-MCM-41. There were also four similar diffraction (100), (110), (200) and (210) peaks in the SAXRD patterns of ASSs. These diffraction peaks proved that the mesoporous structure was produced in both ASSs and Al-MCM-41 [1]. The relative intensities of four diffraction peaks of Al-MCM-41 were stronger than that of ASSs, which was due to the uncalcined surfactants in ASSs, indicating that ASSs had a less highly ordered and hexagonal mesoporous structure compared to Al-MCM-41. In the process of calcination, the framework condensed and the reflections were shifted to higher diffraction angles [26]. In essence, the highly ordered and hexagonal structure of Al-MCM-41 could be clearly demonstrated by SAXRD patterns of Al-MCM-41 [2]. This result was also proved by TEM images of Al-MCM-41. 


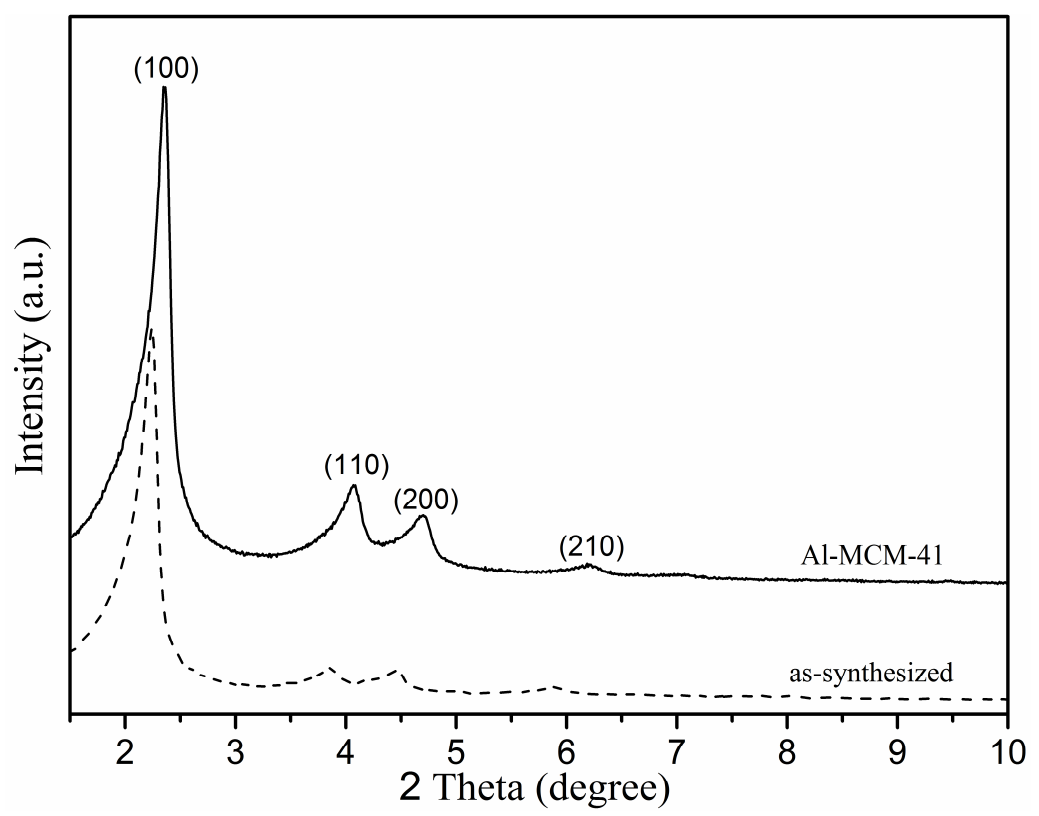

Figure 1. Small-angle X-ray diffraction (SAXRD) patterns of as-synthesized samples (ASSs) and Al-MCM-41.

Figure 2 shows the WAXRD patterns of natural perlite, acid-leached samples, ASSs, and Al-MCM-41. Acid leaching, alkali leaching, hydrothermal reaction and calcination were four important stages in the synthesis process of Al-MCM-41 from natural perlite. The WAXRD pattern of natural perlite showed that the main component of perlite was silica. The silica content accounted for $70.76 \%$ according to the $\mathrm{X}$-ray fluorescence results. After acid leaching, the majority of $\mathrm{Al}$ in natural perlite was removed and amorphous $\mathrm{SiO}_{2}$ was produced. Amorphous $\mathrm{SiO}_{2}$ was treated with sodium hydroxide, and silicon and aluminum sources were acquired. Furthermore, Al-MCM-41 was synthesized via a hydrothermal method and calcination with these silicon and aluminum sources. The WAXRD patterns of ASSs and Al-MCM-41 indicated that the synthesized samples were amorphous $\mathrm{SiO}_{2}$.

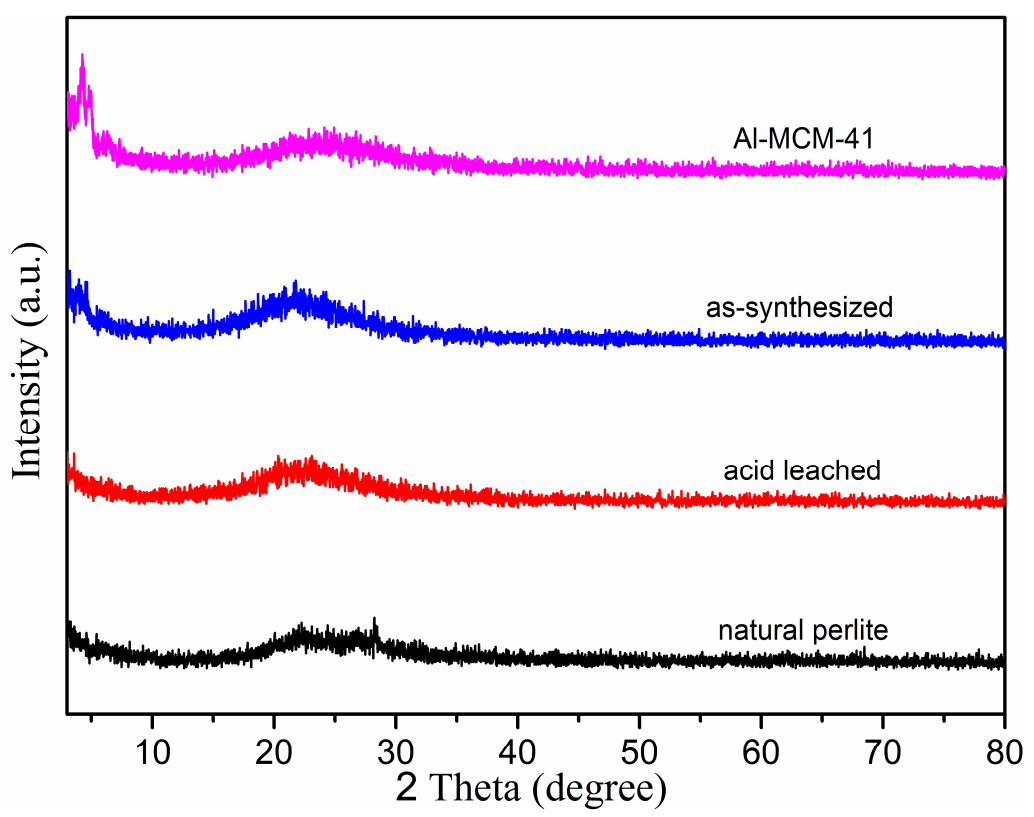

Figure 2. Wide-angle X-ray diffraction (WAXRD) patterns of samples. 
The mesoporous structure of Al-MCM-41 was characterized by TEM, see Figure 3. These images confirmed that the Al-MCM-41 synthesized from natural perlite had a hexagonal and ordered mesopores structure, which was consistent with the SAXRD results. The uniform pore size was $3.0 \mathrm{~nm}$. The channels of mesopores had a hexagonal structure in the direction perpendicular to the pore axis and were long-range ordered in the direction of the pore axis. These results indicated that Al-MCM-41 was successfully synthesized.
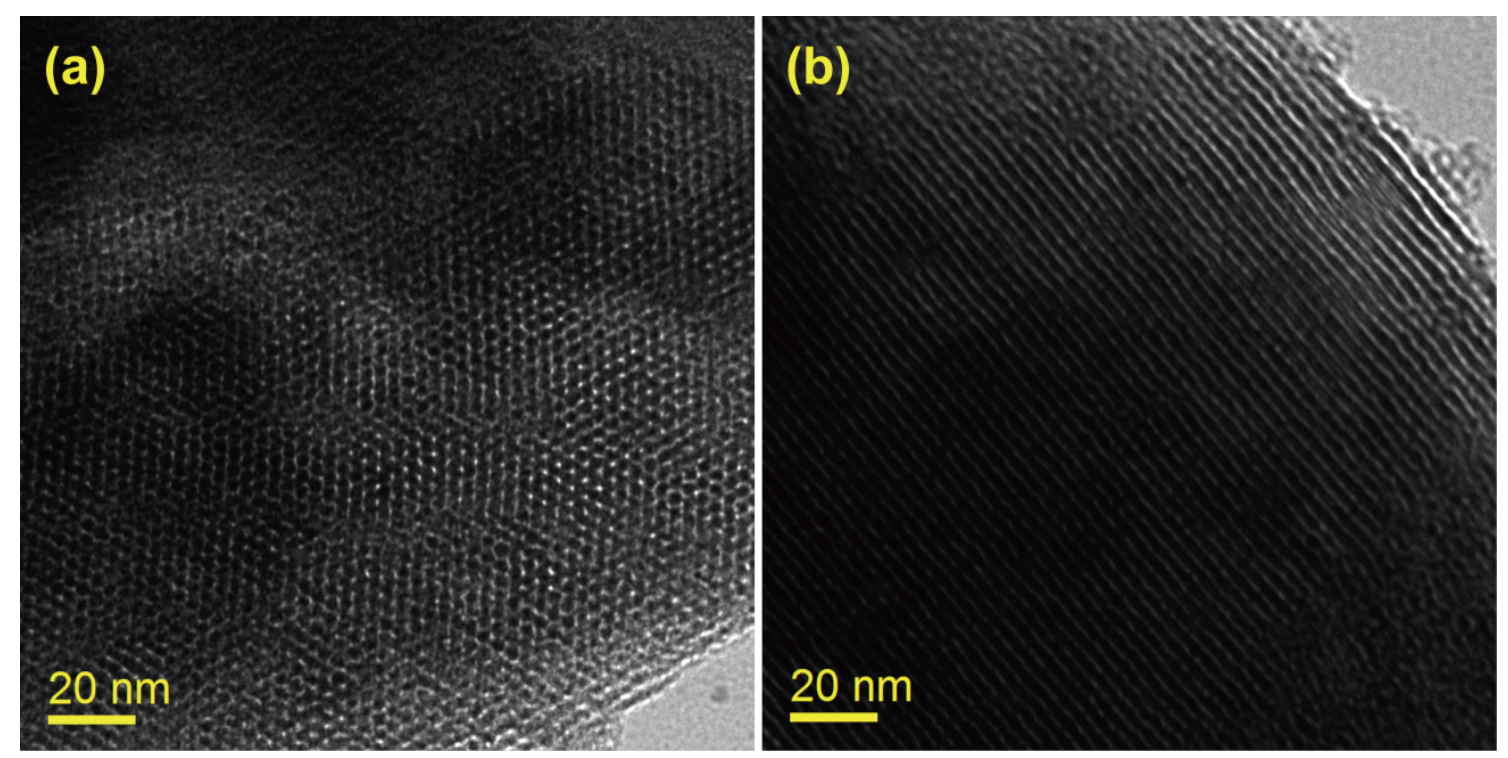

Figure 3. Transmission electron microscopy (TEM) images of Al-MCM-41: (a) the direction perpendicular to the pore axis; (b) the direction of the pore axis.

\subsection{Porosity Measurements}

Figure 4 shows the $\mathrm{N}_{2}$ adsorption-desorption isotherm and pore size distribution curve of Al-MCM-41. On the basis of the IUPAC classification, the isotherm exhibited a typical type IV class [32], which was one of the main characteristics of mesoporous materials. The adsorption isotherm changed slowly at a lower $P / P_{0}$ stage, where nitrogen molecules covered the mesoporous walls with monolayer adsorption at this stage. The significant adsorption was not due to the presence of microporous phases. The $\mathrm{N}_{2}$ adsorption-desorption isotherm had a sharp inflection at $P / P_{0}=0.25-0.4$, which demonstrated that capillary condensation occurred in uniform mesopores. The reason for this phenomenon was that nitrogen molecules covered the mesoporous walls with monolayer and multilayer adsorption. Additionally, a H1-type hysteresis loop was observed [33], which was attributed to the characteristics of mesoporous silica materials [25]. The position of the capillary condensation with respect to the $P / P_{0}$ axis was directly related to the diameter of the mesopore [25]. These results exhibited the presence of uniform mesopores and the hexagonal and ordered mesoporous structure in the final synthesized materials. A sharp peak at $2.5 \mathrm{~nm}$ was clearly observed in the pore size distribution curves, indicating that the pore size was concentrated at $2.5 \mathrm{~nm}$. The average pore size was around $2.8 \mathrm{~nm}$ with a range of $2-6 \mathrm{~nm}$ in diameter. In summary, mesoporous silica materials synthesized from natural perlite had a BET surface area of $1024 \mathrm{~m}^{2} / \mathrm{g}$, pore volume of $0.72 \mathrm{~cm}^{3} / \mathrm{g}$, and an average pore diameter of $2.8 \mathrm{~nm}$. In addition, Table 1 provides a comparison of porous parameters of the synthesized Al-MCM-41 from natural perlite mineral to the reported MCM-41 from various minerals. 
Table 1. Comparison of porous parameters of MCM-41 from various minerals.

\begin{tabular}{|c|c|c|c|c|c|}
\hline Minerals & $\begin{array}{l}\text { Synthesized } \\
\text { MCM-41 }\end{array}$ & $\begin{array}{l}\text { BET Surface Area } \\
\left(\mathrm{m}^{2} / \mathrm{g}\right)\end{array}$ & $\begin{array}{l}\text { Pore Volume } \\
\quad\left(\mathrm{cm}^{3} / \mathrm{g}\right)\end{array}$ & $\begin{array}{l}\text { Average Pore } \\
\text { Diameter (nm) }\end{array}$ & References \\
\hline Bentonite & MCM-41 & 494 & 0.72 & 3.8 & [20] \\
\hline Diatomite & MCM-41 & 1124 & 1.65 & 4.9 & [21] \\
\hline Sepiolite & MCM-41 & 1030 & 1.06 & 3.0 & [22] \\
\hline Talc & MCM-41 & 974 & 1.00 & 2.8 & [24] \\
\hline Attapulgite & Al-MCM-41 & 1030 & 0.96 & 3.7 & [25] \\
\hline Bentonite & Al-MCM-41 & 1018 & 0.72 & 3.0 & [26] \\
\hline Halloysite & Al-MCM-41 & 509 & 0.48 & 3.8 & [28] \\
\hline Kaolin & Al-MCM-41 & 1041 & 0.97 & 3.7 & [29] \\
\hline Rectorite & Al-MCM-41 & 1032 & 0.97 & 2.6 & [30] \\
\hline Perlite & Al-MCM-41 & 1027 & 0.72 & 2.8 & This work \\
\hline
\end{tabular}
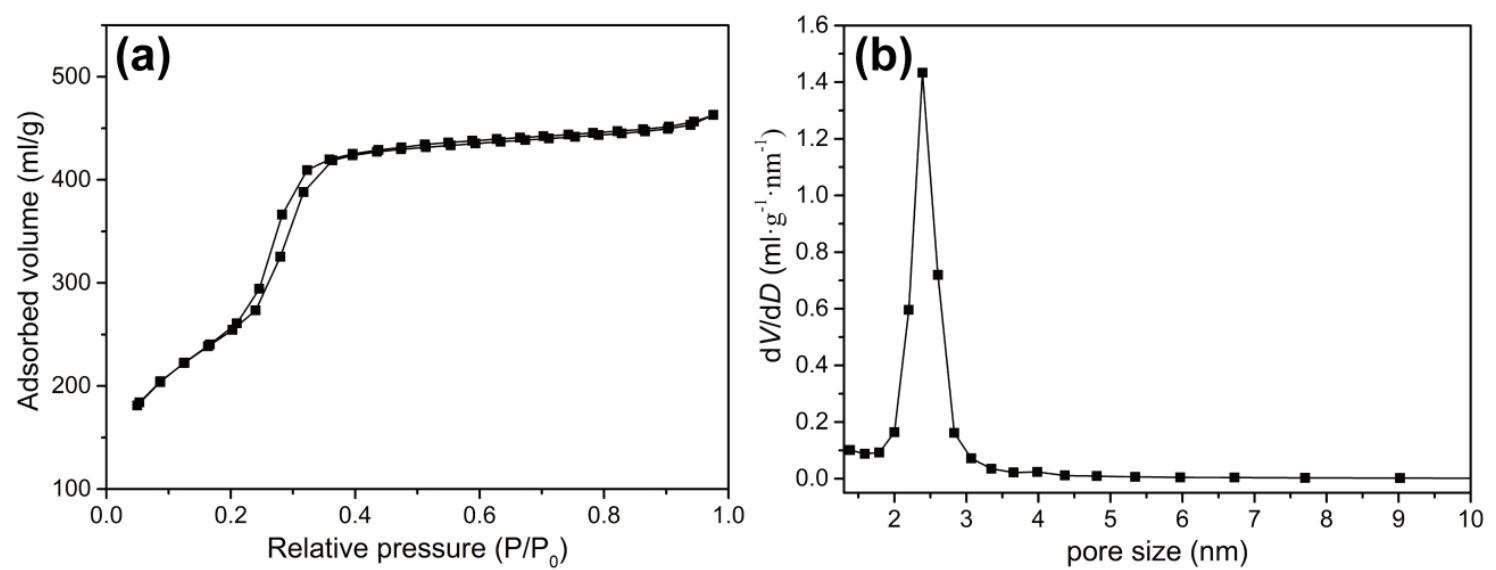

Figure 4. (a) $\mathrm{N}_{2}$ adsorption-desorption isotherms of Al-MCM-41; (b) Barett-Joyner-Halenda (BJH) pore size distribution curves of Al-MCM-41.

\subsection{TG-DTG Analysis}

The thermal behavior of ASSs during calcination was investigated by thermal gravity and differential thermal gravity analysis (TG-DTG). The TG-DTG curves of ASSs showed three main weight losses, see Figure 5. The first weight loss was caused by the thermodesorption of physically adsorbed water $[34,35]$-about $7 \%$ from $25{ }^{\circ} \mathrm{C}$ to $162{ }^{\circ} \mathrm{C}$. The second weight loss was due to the decomposition of the organic materials (breaking of the hydrocarbon chain)—about $13 \%$ and occurring in the temperature range from $162{ }^{\circ} \mathrm{C}$ to $300{ }^{\circ} \mathrm{C}$. The third weight loss from $300{ }^{\circ} \mathrm{C}$ to $1000{ }^{\circ} \mathrm{C}$ was due to combustion of the surfactant and water loss associated with condensation of silanol groups. The loss of weight in the third process was 16\% [36,37]. Moreover, the total weight loss was about $36 \%$ from $25^{\circ} \mathrm{C}$ to $1000{ }^{\circ} \mathrm{C}$.

\subsection{Surface Charge}

The surface charge of mesoporous silica materials was investigated by measuring its zeta potential at different $\mathrm{pH}$ values, see Figure 6. Al-MCM-41 showed a negative surface charge in aqueous solution with the $\mathrm{pH}$ value ranging from 2 to 13, indicating a good dispersion stability. Surface charge of Al-MCM-41 had a sharp inflection ( -18.2 to $-40.2 \mathrm{mV}$ ) with a $\mathrm{pH}$ range from 2.6 to 5.5 and began to increase when the $\mathrm{pH}$ value exceeded 9. The surface charge of Al-MCM-41 presented a slight decrease as the $\mathrm{pH}$ value increased from 5.5 to 9. The negative charges of Al-MCM-41 could provide sites for adsorbing the positively charged ions via electrostatic interaction in an aqueous medium [38], representing a green chemistry approach. 


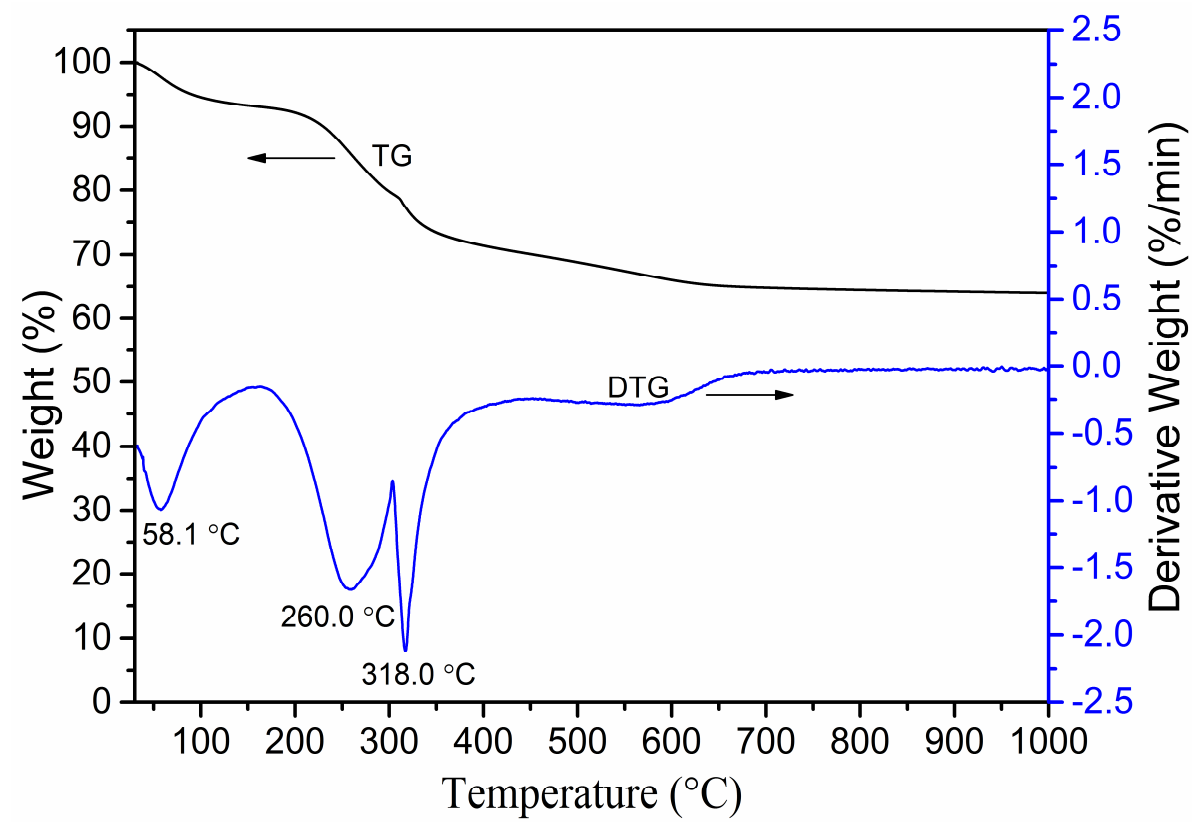

Figure 5. Thermal gravity and differential thermal gravity (TG-DTG) curves of as-synthesized samples (ASSs) with a heating rate of $10^{\circ} \mathrm{C} / \mathrm{min}$.

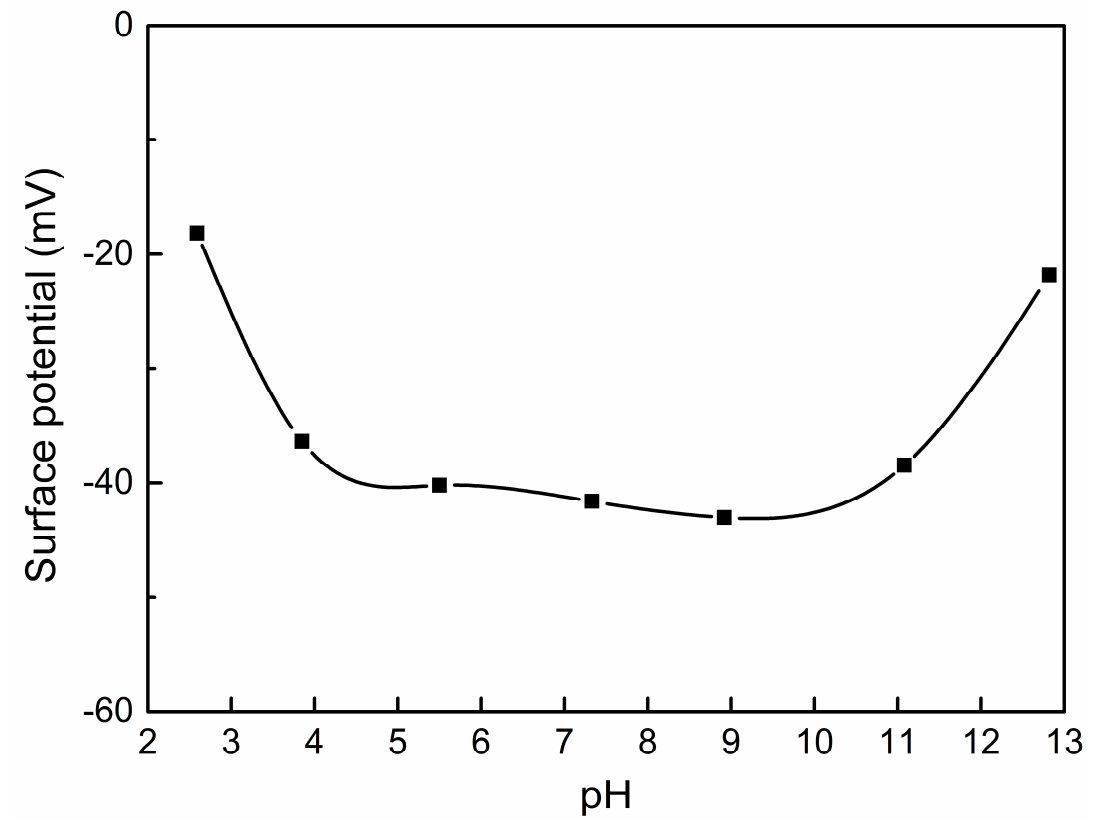

Figure 6. Surface charge of Al-MCM-41.

\subsection{FTIR Spectra}

As shown in Figure 7, the vibrational bands of natural perlite, acid-leached samples, ASSs and Al-MCM-41 were investigated by Fourier-transform infrared analysis. In the FTIR spectrum of natural perlite, the band at $3620 \mathrm{~cm}^{-1}$ was attributed to the $\mathrm{O}-\mathrm{H}$ stretching vibration of inner hydroxyl groups $[39,40]$. The band at $1631 \mathrm{~cm}^{-1}$ was associated with the vibration of adsorbed water molecules [41]. The bands at 1043 and $791 \mathrm{~cm}^{-1}$ were assigned to Si-O stretching vibrations of Si-O-Si and $\mathrm{Si}-\mathrm{O}-\mathrm{Al}$ [41]. The band at $470 \mathrm{~cm}^{-1}$ was ascribed to $\mathrm{O}-\mathrm{Si}-\mathrm{O}$ bending vibration [41]. The band at $1043 \mathrm{~cm}^{-1}$ in the FTIR spectrum of natural perlite was shifted to higher wavenumbers of $1087 \mathrm{~cm}^{-1}$ in FTIR spectrum of acid-leached samples, which indicated the transformation from the in-plane Si-O-Si 
stretching vibration to the out-plane $\mathrm{Si}-\mathrm{O}-\mathrm{Si}$ stretching vibration [30], while other bands remained. These results demonstrated that the surface properties of natural perlite were not changed after acid treatment. The obvious bands at 2924, 2854 and $1480 \mathrm{~cm}^{-1}$ were ascribed to the characteristic peaks of the surfactant alkyl chain in FTIR spectrum of ASSs [26]. This result revealed that ASSs consisted of the surfactants. The characteristic peaks of the surfactants disappeared after calcination, providing evidence that the surfactants were removed.

For ASSs and Al-MCM-41, the stretching vibration bands of adsorbed water molecules at 3430 and $3411 \mathrm{~cm}^{-1}$, and the bending vibration bands of adsorbed water molecules at 1636 and $1630 \mathrm{~cm}^{-1}$, suggested that both ASSs and Al-MCM-41 consisted of adsorbed water. The bands at 1232 and $1240 \mathrm{~cm}^{-1}$ could be assigned to the stretching vibration of external asymmetric Si-O-Si. These bands were typical bands of ordered mesoporous silica materials. The FTIR spectra of natural perlite and acid leached samples did not present the bands at 1232 and $1240 \mathrm{~cm}^{-1}$. The bands at 1070 and $1078 \mathrm{~cm}^{-1}$ were assigned to the stretching vibrations of internal asymmetric Si-O-Si. After calcination, the framework for mesoporous silica materials was formed. This result could be proved by the low to high shift of wavenumbers, assigned to internal and external asymmetric Si-O stretching vibrations, from ASSs to Al-MCM-41 [25]. The bands at 796 and $806 \mathrm{~cm}^{-1}$ were attributed to the symmetric stretching vibration of Si-O-Si [42]. The bands at 445 and $463 \mathrm{~cm}^{-1}$ were assigned to the tetrahedral bending vibration of $\mathrm{Si}-\mathrm{O}-\mathrm{Si}$.

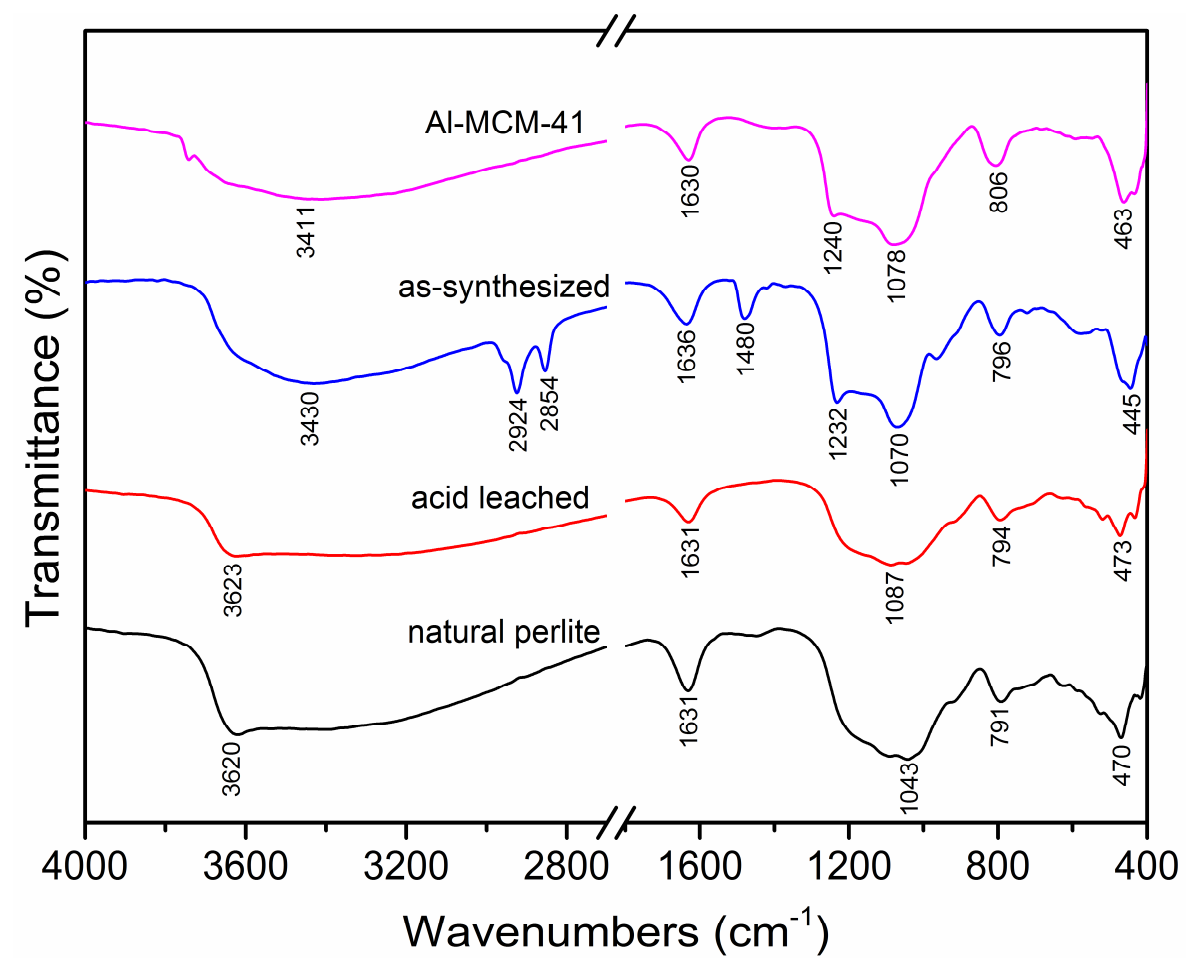

Figure 7. Fourier-transform infrared (FTIR) spectra of samples.

\subsection{Proposed Mechanism from Natural Perlite to Al-MCM-41}

Based on the above results, a proposed mechanism for the synthesis of hexagonal and ordered mesoporous silica materials from natural perlite is suggested. The X-ray fluorescence analysis shows that natural perlite consisted of abundant $\mathrm{SiO}_{2}$ and some metal compounds. In the process of acid leaching, most of the metallic elements, such as Al, can be removed and amorphous silica can be prepared. It is easier to obtain silicon sources from amorphous silica than natural perlite via alkali leaching. At the same time, a small amount of aluminum sources can also be leached in the process of alkali treatment. Aluminum can promote the formation of ordered mesoporous silica materials and improve their surface area [43]. Silicon and aluminum sources adsorb around the surfactants 
(CTAB) by electrostatic attraction and rod micelles are formed. Subsequently, an hexagonally ordered silica-surfactant phase is produced via hydrothermal reaction. The surfactants (CTAB) are removed through calcination at $550{ }^{\circ} \mathrm{C}$. As a result, the $\mathrm{Si}-\mathrm{O}$ framework condenses and rearranges to produce final mesoporous silica materials which have highly hexagonal and ordered mesoporous structures.

\section{Conclusions}

Mesoporous silica materials have been successfully synthesized via hydrothermal treatment using natural perlite as silicon and aluminum sources, without the addition of silica or aluminum reagents. Silicon and aluminum sources can be obtained via acid leaching and alkali leaching from natural perlite. Furthermore, mesoporous silica materials are synthesized under hydrothermal treatment through charge density matching with structure-directing surfactants (CTAB). Calcination removes the surfactants within the pores and Al-MCM-41 exhibits a BET surface area of $1024 \mathrm{~m}^{2} / \mathrm{g}$, pore volume of $0.72 \mathrm{~cm}^{3} / \mathrm{g}$, and an average pore diameter of $2.8 \mathrm{~nm}$-similar to previous research reports. The final products are amorphous $\mathrm{SiO}_{2}$, which show a negative surface charge in aqueous solution. Channels of $\mathrm{Al}-\mathrm{MCM}-41$ have a hexagonal structure in the direction perpendicular to the pore axis and are long-range ordered in the direction of the pore axis. In addition, a proposed chemical mechanism is suggested to expound the synthetic process from natural perlite to mesoporous silica materials. Thus, our method could offer a more benign approach to the general production of MCM-41 materials.

Author Contributions: H.Y. and H.C. (conceiving the project). H.C. (writing initial drafts of the work). H.Y. (writing the final paper). H.C. and S.F. (designing and performing the experiments, characterizing the samples). L.F. and D.C. (helping in checking the drafts of the paper). All authors discussed the results and commented on the manuscript.

Funding: This work was financially supported the National Key R\&D Program of China (2017YFB0310903), the National Natural Science Foundation of China (41572036), the National Science Fund for distinguished Young Scholars (51225403), the Strategic Priority Research Program of Central South University (ZLXD2017005), the Hunan Provincial Science and Technology Project (2016RS2004, 2015TP1006 and 2018WK4023), the Key R\&D Program of Hunan Province (2017GK2251), the Changsha Science and Technology Project (kc1702029) and the Hunan Provincial Co-Innovation Centre for Clean and Efficient Utilization of Strategic Metal Mineral Resources (2014-405).

Conflicts of Interest: The authors declare no conflict of interest.

\section{References}

1. Kresge, C.T.; Leonowicz, M.E.; Roth, W.J.; Vartuli, J.C.; Beck, J.S. Ordered mesoporous molecular sieves synthesized by a liquid-crystal template mechanism. Nature 1992, 359, 710-712. [CrossRef]

2. Beck, J.S.; Vartuli, J.C.; Roth, W.J.; Leonowicz, M.E.; Kresge, C.T.; Schmitt, K.D.; Chu, C.T.-W.; Olson, D.H.; Sheppard, E.W.; McCullen, S.B.; et al. A new family of mesoporous molecular sieves prepared with liquid crystal templates. J. Am. Chem. Sot. 1992, 114, 10834-10843. [CrossRef]

3. Zhang, H.; Sun, H.; Zhang, D.; Zhang, W.; Chen, S.; Li, M.; Liang, P. Nanoconfinement of Ag nanoparticles inside mesoporous channels of MCM-41 molecule sieve as a regenerable and $\mathrm{H}_{2} \mathrm{O}$ resistance sorbent for $\mathrm{Hg}^{0}$ removal in natural gas. Chem. Eng. J. 2019, 361, 139-147. [CrossRef]

4. Reiser, S.; Türk, M. Influence of temperature and high-pressure on the adsorption behavior of $\mathrm{scCO}_{2}$ on MCM-41 and SBA-15. J. Supercrit. Fluids 2019, 144, 122-133. [CrossRef]

5. Rizzi, V.; Prasetyanto, E.A.; Chen, P.; Gubitosa, J.; Fini, P.; Agostiano, A.; Cola, D.L.; Cosma, P. Amino grafted MCM-41 as highly efficient and reversible ecofriendly adsorbent material for the direct blue removal from wastewater. J. Mol. Liq. 2019, 273, 435-446. [CrossRef]

6. Chen, X.; Ching, W.K.; Lam, K.F.; Wei, W.; Yeung, K.L. An investigation of the selective adsorptions of metals on mesoporous $\mathrm{NH}_{2}-\mathrm{MCM}-41$. J. Phys. Chem. C 2016, 120, 18365-18376. [CrossRef]

7. Ahmed, S.; Ramli, A.; Yusup, S. Development of polyethylenimine-functionalized mesoporous Si-MCM-41 for $\mathrm{CO}_{2}$ adsorption. Fuel Process. Technol. 2017, 167, 622-630. [CrossRef]

8. Nkinahamira, F.; Su, T.; Xie, Y.; Ma, G.; Wang, H.; Li, J. High pressure adsorption of $\mathrm{CO}_{2}$ on $\mathrm{MCM}-41$ grafted with quaternary ammonium ionic liquids. Chem. Eng. J. 2017, 326, 831-838. [CrossRef] 
9. Zhang, L.; Li, Y.; Zhou, H. Preparation and characterization of DUB-loaded MCM-41 for adsorption of $\mathrm{CO}_{2}$. Energy 2018, 149, 414-423. [CrossRef]

10. Martínez-Edo, G.; Balmori, A.; Pontón, I.; Martí del Rio, A.; Sánchez-García, D. Functionalized ordered mesoporous silicas (MCM-41): Synthesis and applications in catalysis. Catalysts 2018, 8, 617. [CrossRef]

11. Jeirani, Z.; Soltan, J. Improved formulation of Fe-MCM-41 for catalytic ozonation of aqueous oxalic acid. Chem. Eng. J. 2017, 307, 756-765. [CrossRef]

12. Lin, X.; Zhong, A.; Sun, Y.; Zhang, X.; Song, W.; Lu, R.; Cao, A.; Wan, L. In situ encapsulation of Pd inside the MCM-41 channel. Chem. Commun. 2015, 51, 7482-7485. [CrossRef]

13. Wang, Y.; Zhao, Q.; Han, N.; Bai, L.; Li, J.; Liu, J.; Che, E.; Hu, L.; Zhang, Q.; Jiang, T.; et al. Mesoporous silica nanoparticles in drug delivery and biomedical applications. Nanomed. Nanotechnol. Biol. Med. 2015, 11, 313-327. [CrossRef]

14. Brezoiu, A.-M.; Deaconu, M.; Nicu, I.; Vasile, E.; Mitran, R.-A.; Matei, C.; Berger, D. Heteroatom modified MCM-41-silica carriers for lomefloxacin delivery systems. Microporous Mesoporous Mater. 2019, 275, 214-222. [CrossRef]

15. Varache, M.; Bezverkhyy, I.; Saviot, L.; Bouyer, F.; Baras, F.; Bouyer, F. Optimization of MCM-41 type silica nanoparticles for biological applications: Control of size and absence of aggregation and cell cytotoxicity. J. Non-Cryst. Solids 2015, 408, 87-97. [CrossRef]

16. Zhao, Q.; Fu, L.; Jiang, D.; Xi, Y.; Yang, H. A nanoclay-induced defective g- $\mathrm{C}_{3} \mathrm{~N}_{4}$ photocatalyst for highly efficient catalytic reactions. Chem. Commun. 2018, 54, 8249-8252. [CrossRef]

17. Fu, L.; Yan, Z.; Zhao, Q.; Yang, H. Novel 2D nanosheets with potential applications in heavy metal purification: A review. Adv. Mater. Interfaces 2018, 5, 1801094. [CrossRef]

18. Yan, Z.; Yang, H.; Ouyang, J.; Tang, A. In situ loading of highly-dispersed CuO nanoparticles on hydroxyl group-rich $\mathrm{SiO}_{2}$-AlOOH composite nanosheets for $\mathrm{CO}$ catalytic oxidation. Chem. Eng. J. 2017, 316, 1035-1046. [CrossRef]

19. Zhang, Y.; Tang, A.; Yang, H.; Ouyang, J. Applications and interfaces of halloysite nanocomposites. Appl. Clay Sci. 2016, 119, 8-17. [CrossRef]

20. Ali-dahmane, T.; Adjdir, M.; Hamacha, R.; Villieras, F.; Bengueddach, A.; Weidler, P.G. The synthesis of MCM-41 nanomaterial from algerian bentonite: The effect of the mineral phase contents of clay on the structure properties of MCM-41. C. R. Chim. 2014, 17, 1-6. [CrossRef]

21. Yu, Z.; Wang, Y.; Liu, X.; Sun, J.; Sha, G.; Yang, J.; Meng, C. A novel pathway for the synthesis of ordered mesoporous silica from diatomite. Mater. Lett. 2014, 119, 150-153. [CrossRef]

22. Jin, S.; Cui, K.; Guan, H.; Yang, M.; Liu, L.; Lan, C. Preparation of mesoporous MCM-41 from natural sepiolite and its catalytic activity of cracking waste polystyrene plastics. Appl. Clay Sci. 2012, 56, 1-6. [CrossRef]

23. Zhou, C.; Sun, T.; Gao, Q.; Alshameri, A.; Zhu, P.; Wang, H.; Qiu, X.; Ma, Y.; Yan, C. Synthesis and characterization of ordered mesoporous aluminosilicate molecular sieve from natural halloysite. J. Taiwan Inst. Chem. Eng. 2014, 45, 1073-1079. [CrossRef]

24. Du, C.; Yang, H. Simple synthesis and characterization of nanoporous materials from talc. Clays Clay Min. 2009, 57, 290-301. [CrossRef]

25. Yang, H.; Tang, A.; Ouyang, J.; Li, M.; Mann, S. From natural attapulgite to mesoporous materials: Methodology, characterization and structural evolution. J. Phys. Chem. B 2010, 114, 2390-2398. [CrossRef] [PubMed]

26. Yang, H.; Deng, Y.; Du, C.; Jin, S. Novel synthesis of ordered mesoporous materials Al-MCM-41 from bentonite. Appl. Clay Sci. 2010, 47, 351-355. [CrossRef]

27. Jin, J.; Ouyang, J.; Yang, H. One-step synthesis of highly ordered Pt/MCM-41 from natural diatomite and the superior capacity in hydrogen storage. Appl. Clay Sci. 2014, 99, 246-253. [CrossRef]

28. Xie, Y.; Zhang, Y.; Ouyang, J.; Yang, H. Mesoporous material Al-MCM-41 from natural halloysite. Phys. Chem. Miner. 2014, 41, 497-503. [CrossRef]

29. Du, C.; Yang, H. Investigation of the physicochemical aspects from natural kaolin to Al-MCM-41 mesoporous materials. J. Colloid Interface Sci. 2012, 369, 216-222. [CrossRef]

30. Chen, H.; Yang, H.; Xi, Y. Highly ordered and hexagonal mesoporous silica materials with large specific surface from natural rectorite mineral. Microporous Mesoporous Mater. 2019, 279, 53-60. [CrossRef]

31. Zujovic, Z.; Wheelwright, W.V.K.; Kilmartin, P.A.; Hanna, J.V.; Cooney, R.P. Structural investigations of perlite and expanded perlite using ${ }^{1} \mathrm{H},{ }^{27} \mathrm{Al}$ and ${ }^{29} \mathrm{Si}$ solid-state NMR. Ceram. Int. 2018, 44, 2952-2958. [CrossRef] 
32. Peng, K.; Fu, L.; Ouyang, J.; Yang, H. Emerging parallel dual 2D composites: Natural clay mineral hybridizing $\mathrm{MoS}_{2}$ and interfacial structure. Adv. Funct. Mater. 2016, 26, 2666-2675. [CrossRef]

33. Yan, Z.; Fu, L.; Yang, H.; Ouyang, J. Amino-functionalized hierarchical porous $\mathrm{SiO}_{2}-\mathrm{AlOOH}$ composite nanosheets with enhanced adsorption performance. J. Hazard. Mater. 2018, 344, 1090-1100. [CrossRef]

34. Peng, K.; Yang, H. Carbon hybridized montmorillonite nanosheets: Preparation, structural evolution and enhanced adsorption performance. Chem. Commun. 2017, 53, 6085-6088. [CrossRef]

35. Li, X.; Yang, Q.; Ouyang, J.; Yang, H.; Chang, S. Chitosan modified halloysite nanotubes as emerging porous microspheres for drug carrier. Appl. Clay Sci. 2016, 126, 306-312. [CrossRef]

36. Majchrzak-Kucęba, I.; Nowak, W. Characterization of MCM-41 mesoporous materials derived from polish fly ashes. Int. J. Miner. Process. 2011, 101, 100-111. [CrossRef]

37. Kumar, P.; Mal, N.; Oumi, Y.; Yamana, K.; Sano, T. Mesoporous materials prepared using coal fly ash as the silicon and aluminium source. J. Mater. Chem. 2001, 11, 3285-3290. [CrossRef]

38. Long, M.; Zhang, Y.; Huang, P.; Chang, S.; Hu, Y.; Yang, Q.; Mao, L.; Yang, H. Emerging nanoclay composite for effective hemostasis. Adv. Funct. Mater. 2018, 28, 1704452. [CrossRef]

39. Zhang, Y.; Long, M.; Huang, P.; Yang, H.; Chang, S.; Hu, Y.; Tang, A.; Mao, L. Intercalated 2D nanoclay for emerging drug delivery in cancer therapy. Nano Res. 2017, 10, 2633-2643. [CrossRef]

40. Peng, K.; Fu, L.; Li, X.; Ouyang, J.; Yang, H. Stearic acid modified montmorillonite as emerging microcapsules for thermal energy storage. Appl. Clay Sci. 2017, 138, 100-106. [CrossRef]

41. Majouli, A.; Younssi, S.A.; Tahiri, S.; Albizane, A.; Loukili, H.; Belhaj, M. Characterization of flat membrane support elaborated from local moroccan perlite. Desalination 2011, 277, 61-66. [CrossRef]

42. Amama, P.B.; Lim, S.; Ciuparu, D.; Pfefferle, L.; Haller, G.L. Hydrothermal synthesis of MCM-41 using different ratios of colloidal and soluble silica. Microporous Mesoporous Mater. 2005, 81, 191-200. [CrossRef]

43. Xie, Y.; Tang, A.; Yang, H. Synthesis of nanoporous materials Al-MCM-41 from natural halloysite. Nano 2015, 10, 1550005. [CrossRef]

(C) 2019 by the authors. Licensee MDPI, Basel, Switzerland. This article is an open access article distributed under the terms and conditions of the Creative Commons Attribution (CC BY) license (http://creativecommons.org/licenses/by/4.0/). 